\title{
IBM Aplikasi Keuangan Pada Sekolah Dasar Luhuring Budi Kecamatan Rumbai
}

\author{
Nurliana Nasution*1, Mhd Arief Hasan² \\ 1,2 Program Studi Teknik Informatika, Fakultas Ilmu Komputer, Universitas Lancang Kuning \\ *e-mail: nurliananst@unilak.ac.id ${ }^{1}$, m.arif@unilak.ac.id²
}

\begin{abstract}
Elementary school is the most basic level of education for formal education in Indonesia. In improving education the quality of education services for elementary school students is very important. Luhuring Budi Elementary School is an elementary school located in Agrowitasa Subdistrict, Rumbai District, Pekanbaru City which has a vision (Together in Achievement, Moral in Karimah, Honest and Trustworthy, Obedient in Worship, Independent and Love the Environment and with a Malay Culture. This Luhur Elementary School continues to make improvements, evaluation and development. Especially regarding the management of good financial governance. This new school which was founded in 2019 does not yet have a good system for financial management in its schools. So that the School and foundations often experience difficulties in conducting activities on Managing School Tuition Fee Data, Managing Development Fee Data. Managing Uniform Fee Data. Managing Other Financing Data. The need for a good financial management system is a means and infrastructure for schools and foundations to monitor their school finances properly. So that they can properly measure the ability of their financial resources. So that with this system it is hoped that schools can be helped to create activities based on the amount of budget they have. This training is in the form of providing financial application products to SDIT Luhuring Budi. Before being given it is necessary to hold training and mentoring. So that the existing applications can really benefit the partners. Because the purpose of the Information System is to make it easier for users to carry out their activities. IBM was implemented in early 2020. Existing applications provide benefits to schools. This was proven after the training monitoring was carried out using a post-training questionnaire.
\end{abstract}

Keywords: Application, Elementary School, Information System,, Financial, Training

\begin{abstract}
Abstrak
Sekolah Dasar merupakan jenjang pendidikan paling dasar untuk pendidikan formal di Indonesia. Dalam meningkatkan pendidikan mutu layananan pendidikan bagi siswa sekolah dasar amatlah penting. Sekolah Dasar Luhuring Budi adalah Sekolah Dasar yang bertempat di Kelurahan Agrowitasa Kecamatan Rumbai Kota Pekanbaru yang mempunyai Visi (Bersama Dalam Prestasi, Berakhlakul Karimah, Jujur dan Amanah, Taat Beribadah, Mandiri dan Cinta Lingkungan Serta Berbudaya Melayu. Dalam pencapaian tujuan visi dan misi tersebut saat ini Sekolah Dasar Luhur terus melakukan pembenahan, evaluasi dan pengembangan. Terutama mengenai manajemen pengelolaan tata kelola keuangan yang baik. Sekolah yang baru berdiri tahun 2019 ini belum mempunyai sistem yang baik untuk pengelolaan keuangan yang ada disekolahnya. Sehingga Pihak Sekolah maupun yayasan sering mengalami kesulitan untuk melakukan terhadap kegiatan Mengelola Data Uang SPP Sekolah, Mengelola Data Uang Pembangunan. Mengelola Data Uang Seragam. Mengelola Data Pembiayaan Lainnya.Perlunya sistem pengelolaan keuangan yang baik ini adalah sebagai sarana dan prasana bagi pihak sekolah dan yayasan untuk memonitoring keuangan sekolah mereka dengan baik. Sehingga mereka bisa mengukur dengan baik kemampuan terhadap sumber daya keuangan yang dimiliki. Sehingga dengan adanya sistem tersebut diharapkan sekolah bisa terbantu untuk membuat kegiatan berdasarkan jumlah anggaran yang dimiliki.Pelatihan ini berupa memberikan produk aplikasi keuangan kepada SDIT Luhuring Budi. Sebelum diberikan maka perlu diadakannya pelatihan dan pendampingan. Agar aplikasi yang ada betul-betul dirasakan manfaatnya oleh mitra. Karena tujuan Sistem Informasi itu dilakukan agar memberikan kemudahan kepada pengguna dalam melaksanakan aktifitasnya. IBM ini dilaksanakan pada awal tahun 2020. Aplikasi yang ada memberikan manfaat terhadap sekolah. Hal ini terbukti setelah di adakannya monitoring pelatihan menggunakan kuisioner paska pelatihan.
\end{abstract}

Kata kunci: Aplikasi, Sekolah Dasar, Sistem Informasi, Keuangan, Pelatihan

\section{PENDAHULUAN}

1.1 Latar Belakang 
Sekolah Dasar merupakan jenjang pendidikan paling dasar untuk pendidikan formal di Indonesia. Sekolah dasar yang dapat ditempuh selama 6 tahun merupakan sudah menjadi kewajiban pendidikan bagi seluruh warga negara Indonesia. Siswa mengikuti seluruh materi kegiatan pendidikan mulai kelas 1 sampai dengan kelas 6 . Hal ini menjadi syarat bagi mereka untuk bisa melanjutkan ke tingkat pendidikan selanjutnya yakni Sekolah Lanjutan Tingkat Pertama (SLTP).

Dalam meningkatkan pendidikan mutu layananan pendidikan bagi siswa sekolah dasar amatlah penting. Maka pelayanan-pelayanan pendidikan dan bimbingan terus diupayakan sedemikian rupa agar siswa dapat memahami dan menghayati secara menyeluruh terutama pembentukan sikap diri siswa menuju kedewasaan. Usaha untuk menjadikan pendidikan sekolah dasar dengan tuntunan mutu layanan terbaik juga harus ditinjau dengan pengelolaan keuangan yang baik pula.

Sekolah Dasar Luhuring Budi adalah Sekolah Dasar yang bertempat di Kelurahan Agrowitasa Kecamatan Rumbai Kota Pekanbaru yang mempunyai Visi (Bersama Dalam Prestasi, Berakhlakul Karimah, Jujur dan Amanah, Taat Beribadah, Mandiri dan Cinta Lingkungan Serta Berbudaya Melayu. Dan Misi yakni :

1. Menciptakan Peserta Didik yang cerdas, bertaqwa, berakhlakul karimah, aktif, kreatif, efektif, menantang, menyenangkan dan mengasikan.

2. Mengembangkan manajemmen berbasis sekolah (MBS) yang mengacu pada kurikulum SD Luhurig Budi Kota Pekanbaru.

3. Menciptakan Kerukunan Kekompakan dan kerjasama yang baik, harmonis dengan Orang Tua peserta didik, Pihak Sekolah, Yayasan dan Masyarakat serta dunia usaha lainnya.

4. Mengembangkan Budaya Melayu (Riau)

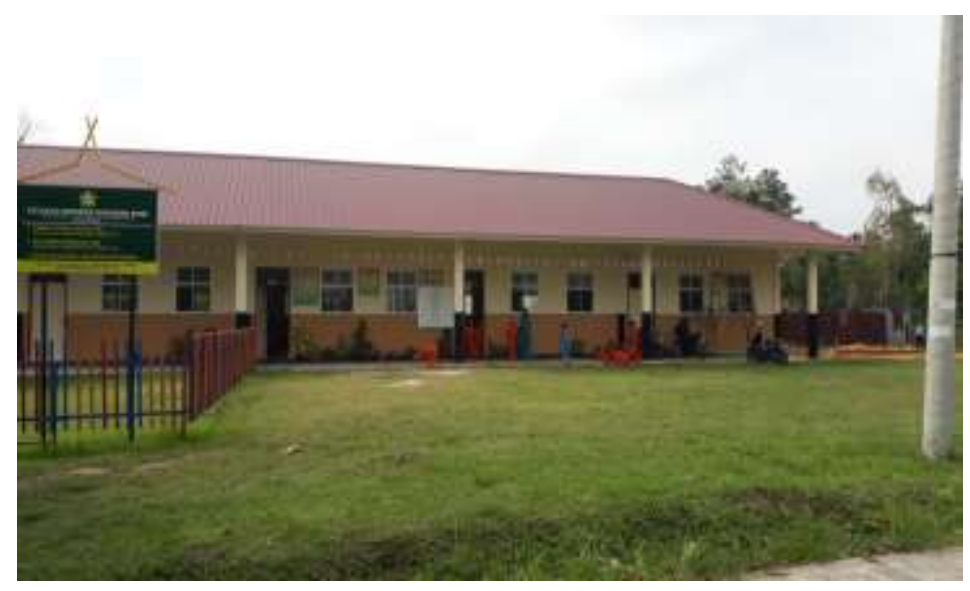

Gambar 1. SDIT Luhuring Budi Kelurahan Agrowisata

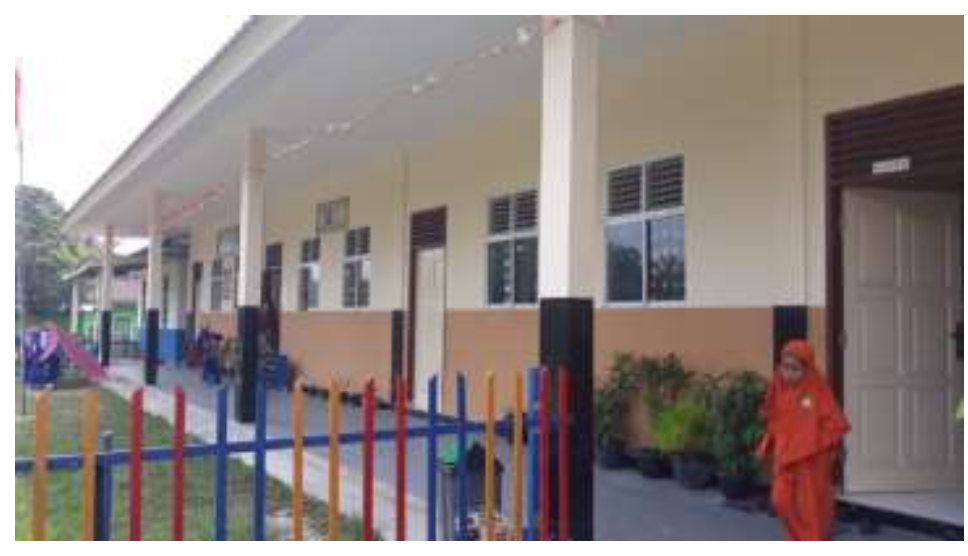

Gambar 2. Ruang Kelas SDIT Luhuring Budi 
Dalam pencapaian tujuan visi dan misi tersebut saat ini Sekolah Dasar Luhur terus melakukan pembenahan, evaluasi dan pengembangan. Terutama mengenai manajemen pengelolaan tata kelola keuangan yang baik. Sekolah yang baru berdiri tahun 2019 ini belum mempunyai sistem yang baik untuk pengelolaan keuangan yang ada disekolahnya. Sehingga Pihak Sekolah maupun yayasan sering mengalami kesulitan untuk melakukan terhadap kegiatan Mengelola Data Uang SPP Sekolah, Mengelola Data Uang Pembangunan. Mengelola Data Uang Seragam. Mengelola Data Pembiayaan Lainnya.

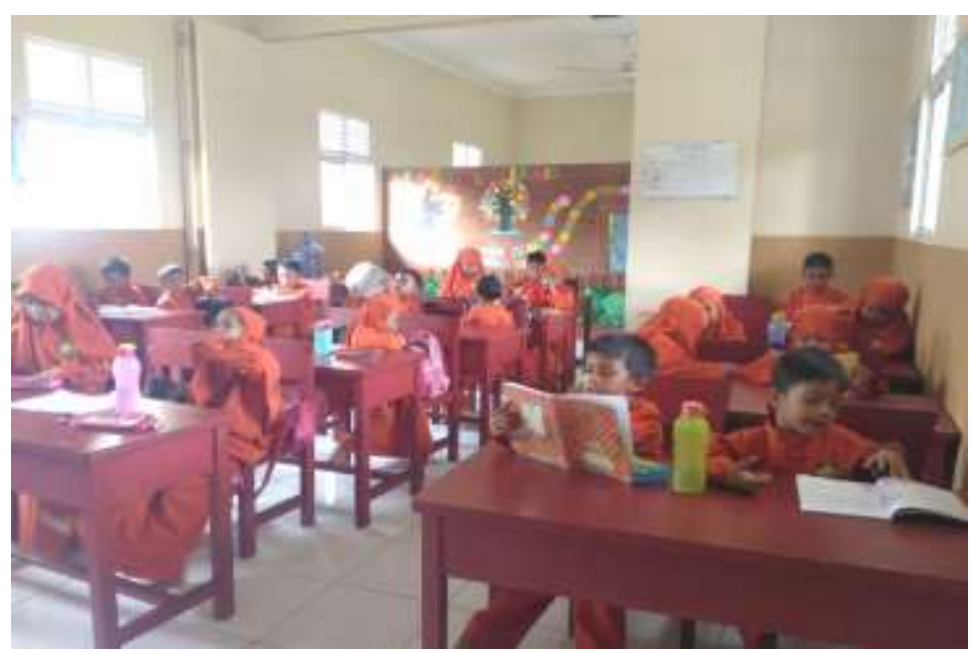

Gambar 3. Suasana Ruang Belajar Mengajar

Perlunya sistem pengelolaan keuangan yang baik ini adalah sebagai sarana dan prasana bagi pihak sekolah dan yayasan untuk memonitoring keuangan sekolah mereka dengan baik (Angelia et al., 2018; Hasan et al., 2017; Hasan \& Rianto, 2017; Kosasi \& Eka Yuliani, 2015)(Kustiyahningsih, 2013). Sehingga mereka bisa mengukur dengan baik kemampuan terhadap sumber daya keuangan yang dimiliki. Sehingga dengan adanya sistem tersebut diharapkan sekolah bisa terbantu untuk membuat kegiatan berdasarkan jumlah anggaran yang dimiliki. Pelatihan sejenis sudah dilakukan tim pengabdian diantaranya pelatihan pembuatan aplikasi android (Nasution et al., 2018), Pelatihan CMS dan Konten Digital Jurnalistik (Nasution \& Hasan, 2019), Aplikasi Ujian Online (Nasution et al., 2020), Pelatihan Aplikasi untuk LPPM (Nasution, 2018). Semua pelatihan tersebut merupakan bagian tak terlepaskan dari keberhasilan pengabdian masyarakat ini.

\subsection{Permasalahan Mitra}

Calon target dari IbM adalah Sekolah Dasar Luhuring Budi Kelurahan Agrowisata Kecamatan Rumbai Kota Pekanbaru. Sekolah yang baru berdiri ini masih mempunyai keterbatasan dalam sarana dan prasarana yang mereka miliki.Terutama mengenai masalah pengelolaan keuangan sekolah. Setelah diadakan wawancara dengan pihak sekolah dan yayasan mereka sangat menginginkan sekali sebuah sistem pengelolaan yang baik untuk sekolah tersebut. Sehingga pelaksanaan kegiatan sekolah bisa di ukur dari anggaran yang sudah disetujui sebelumnya.

Berdasarkan uraian diatas yang merupakan hasil justifikasi antara tim IbM dan calon mitra, maka permasalahan yang dihadapi oleh calon mitra adalah sebagai berikut :

a. Mitra yang belum memiliki sistem pengelolaan keuangan yang baik.

b. Mitra yang menginginkan kegiatan sekolah berbasis anggaran

c. Mitra yang menginginkan laporan keuangan, neraca saldo, pembiayaan sekolah, keuangan masuk yang dapat di buat secara cepat dan akurat. 


\section{METODE}

Metode pelaksanaan kegiatan IBM ini dilakukan di Sekolah Dasar Luhuring Budi Kelurahan Agrowisata Kecamatan Rumbai Kota Pekanbaru ini dengan diagram dibawah ini.

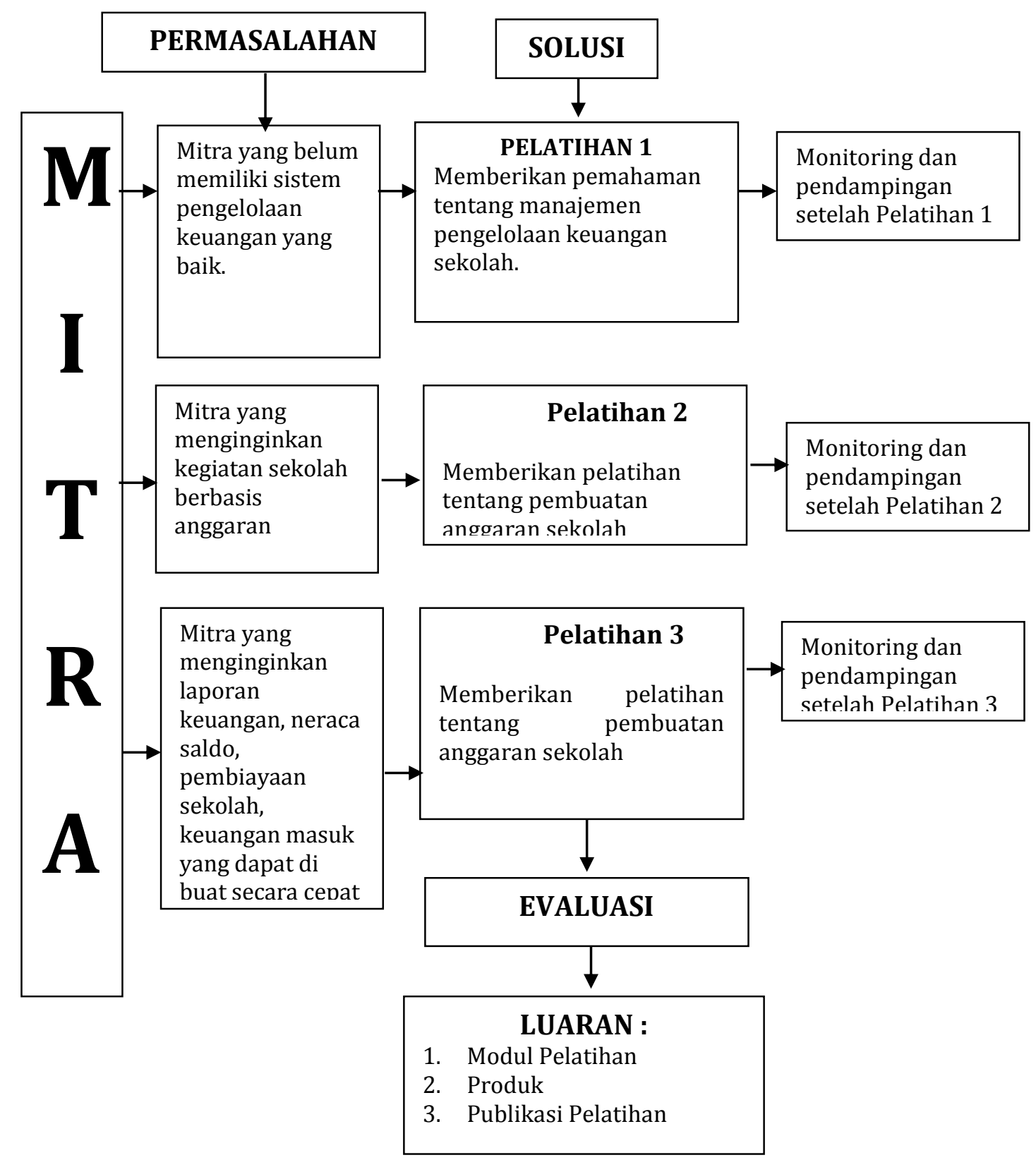

Gambar 4. Metodelogi Penelitian

Pelatihan ini berupa memberikan produk aplikasi keuangan kepada SDIT Luhuring Budi. Sebelum diberikan maka perlu diadakannya pelatihan dan pendampingan. Agar aplikasi yang ada betul-betul dirasakan manfaatnya oleh mitra. Karena tujuan Sistem Informasi itu dilakukan agar memberikan kemudahan kepada pengguna dalam melaksanakan aktifitasnya (Hasan \& Zamzami, 2017),(Hasan \& Rianto, 2017). 


\section{HASIL DAN PEMBAHASAN}

\subsection{Road Map Pengabdian}

Pengabdian ini dibagi dalam beberapa tahap kegiatan yang dilakukan oleh para narasumber/dosen bersama tim Pengurus Sekolah Dasar Luhuring Budi Yayasan Generus Luhuring Budi Kota Pekanbaru, pada awal pertama pengabdian tim berusaha menemukan aplikasi yang tepat untuk diterapkan di Sekolah Dasar Luhuring Budi Kelurahan Agrowisata Kecamatan Rumbai Kota Pekanbaru. Kemudian setelah menemukan software yang tepat tim pengabdian mulai membuat panduan penggunaan yang nantinya untuk disosialisasikan kepada pihak sekolah

Berikut merupakan tabel rodmap kegiatan yang dilakukan tim pengabdian dalam melaksanakan kegiatan PKM ini.

Tabel 1. Roadmap Pengabdian

\begin{tabular}{|c|c|c|c|}
\hline No & Waktu Kegiatan & Uraian Kegiatan & Hasil \\
\hline 1. & November 2019 & $\begin{array}{l}\text { Menemukan / Merancang } \\
\text { Aplikasi yang tepat untuk SD } \\
\text { Luhuring Budi. }\end{array}$ & $\begin{array}{l}\text { Disetujuinya } \\
\text { Kebutuhan aplikasi keuangan } \\
\text { yang dimaksud }\end{array}$ \\
\hline 2. & Desember 2020 & $\begin{array}{l}\text { Membuat panduan manual dari } \\
\text { penggunaan aplikasi keuangan } \\
\text { SD Luhuring Budi }\end{array}$ & $\begin{array}{l}\text { Terwujudnya Draft Panduan } \\
\text { Penggunaan aplikasi Keuangan } \\
\text { SD Luhuring Budi }\end{array}$ \\
\hline 3. & $\begin{array}{l}\text { Desember - } \\
\text { Januari } \\
2020\end{array}$ & $\begin{array}{l}\text { Pelatihan/sosialisasi Aplikasi } \\
\text { Keuangan Sekolah Dasar } \\
\text { Luhuring Budi Kelurahan } \\
\text { Agrowisata Kecamatan Rumbai } \\
\text { Kota Pekanbaru }\end{array}$ & $\begin{array}{l}\text { Operator Sekolah Mahir } \\
\text { menggunakan aplikasi ini } \\
\text { sehingga bisa digunakan untuk } \\
\text { kegiatan operasional Sekolah }\end{array}$ \\
\hline 4. & $\begin{array}{l}\text { Januari-Februari } \\
2020\end{array}$ & Pendampingan Pasca pelatihan & $\begin{array}{l}\text { Kegiatan selanjutnya adalah } \\
\text { pendampingan pasca pelatihan } \\
\text { dengan penerapan langsung di } \\
\text { Sekolah Dasar Luhuring Budi }\end{array}$ \\
\hline
\end{tabular}

Aplikasi Keuangan yang dilatih pada pelatihan ini adalah aplikasi keuangan dalam format excel yang didalamnya sudah tersedia menu data sekolah, data siswa. Login user. Transaksi keuangan sekolah. Aplikasi ini menyediakan beberapa laporan-laporan yang dibutuhkan oleh pihak sekolah. Seperti Laporan Pembayaran, Laporan Pelunasan, dan Laporan Tunggakan Laporan SPP dan laporan lainnya. Adapun layout dari aplikasi tersebut bisa dilihat pada gambar berikut.

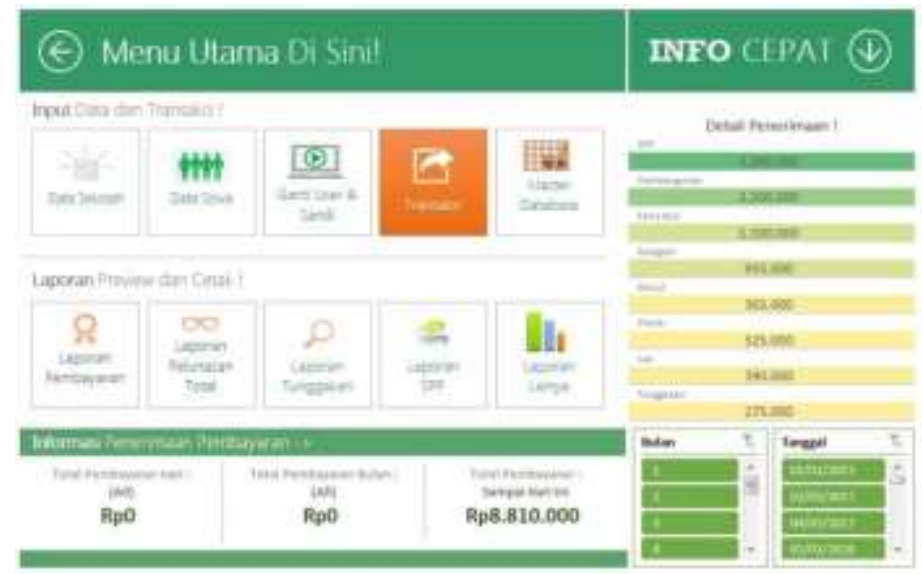

Gambar 5. Menu Utama Aplikasi Keuangan Sekolah 
Pada Gambar 5 merupakan interface utama dari aplikasi keuangan sekolah ini contoh menu pembayaran uang sekolah. Menu utaa ini memudahakan pengguna dalam mengenali fitur fitur yang ada pada aplikasi ini.

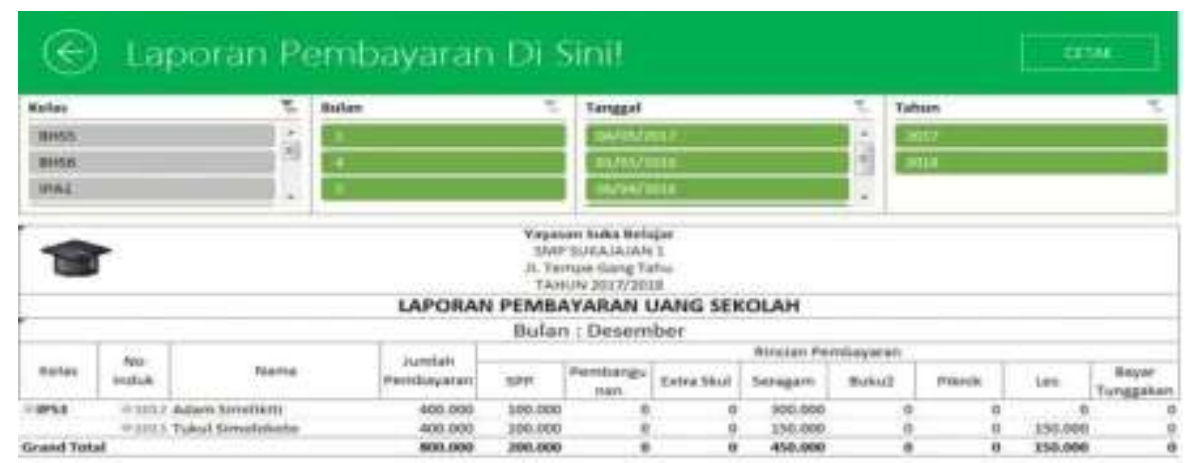

Gambar 6. Menu Laporan Pembayaran Aplikasi Keuangan Sekolah

Pada Gambar 6 merupakan contoh menu pembayaran uang sekolah. Setiap siswa dapat dipantau mengenai pembayaran yang telah mereka lakukan ke sekolah. Sehingga nantinya menghasilkan print layot pembayaran yang ditunjukkan pada gambar 6 .

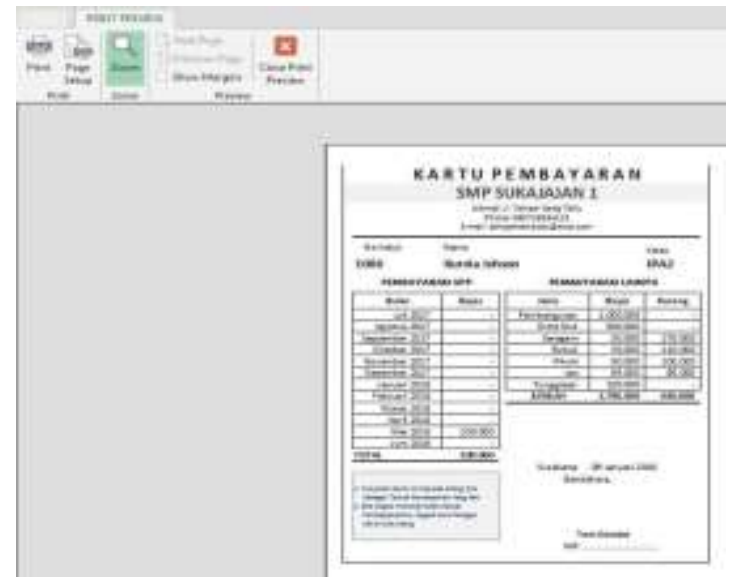

Gambar 7. Menu Kartu Pembayaran

Pada Gambar 7 merupakan contoh dari kartu pembayaran sekolah. Disini mencakup semua draft pembayaran yang telah dilakukan oleh pihak siswa kepada sekolah. Layout print ini nantinya akan di print dan dibagikan kepada orang tua sekolah melalui bendahara sekolah.

\subsection{Hasil Pengabdian}

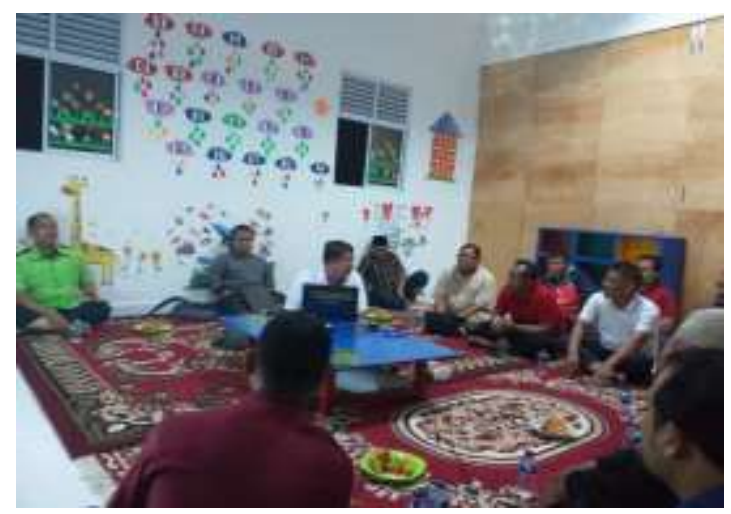

Gambar 8. Suasana Sosialisasi dengan Pengurus Yayasan 


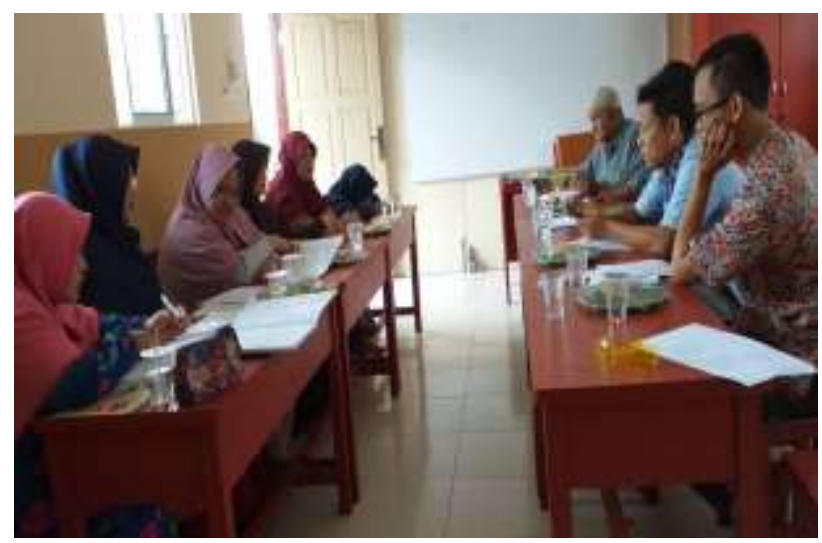

Gambar 9. Suasana Sosialisasi dengan Para Dewan Guru

Pada akhir dari kegiatan masyarakat tim pengabdian melakukan proses evaluasi terhadap materi yang telah diberikan. Evaluasi tersebut diberikan kepada pihak mitra guna untuk mengukur pemahaman mitra terhadap aplikasi yang diberikan. Adapun hasil dari penilaian diukur menggunakan kuisioner yang sudah disiapkan oleh tim pengabdian. Berikut Hasil kuisioner yang disajikan kepada mitra.

Tabel 2. Kuisioner Penilaian Hasil Pengabdian

\begin{tabular}{|c|c|c|c|c|}
\hline \multirow{2}{*}{ Item Penilaian } & \multicolumn{4}{|c|}{ Penilaian } \\
\hline & STS & TS & $\mathrm{S}$ & SS \\
\hline $\begin{array}{l}\text { Apakah materi pelatihan sudah sesuai dengan kebutuhan SD } \\
\text { Luhuring Budi? }\end{array}$ & & & & $\mathrm{X}$ \\
\hline $\begin{array}{l}\text { Apakah materi pelatihan dirasakan sangat bermanfaat dan } \\
\text { memberikan manfaat yang besar kepada SD Luhuring Budi? }\end{array}$ & & & & $\mathrm{X}$ \\
\hline Apakah kualitas materi/handout/Multimedia sudah memadai? & & & & $\mathrm{X}$ \\
\hline Apakah materi Prinsip-prinsip aplikasi sangat mudah dipahami? & & & & $\mathrm{X}$ \\
\hline Apakah penyaji menguasai materi pelatihan? & & & & $\mathrm{X}$ \\
\hline Apakah terdapat kesesuaian antara topik dan presentasi? & & & & $\mathrm{X}$ \\
\hline Apakah penyelenggaraan pelatihan efektif dan efesien? & & & & $\mathrm{X}$ \\
\hline
\end{tabular}

Selain evaluasi materi di atas, tim PKM juga mengevaluasi kemampuan para peserta setelah diberi pelatihan Myob accounting apakah tingkat kemampuan pengetahuan mereka terhadap Myob Accounting semakin bertambah atau tidak, setelah dievaluasi ternyata para peserta mempunyai kemampuan terhadap materi Myob Accounting adalah sebagai berikut :

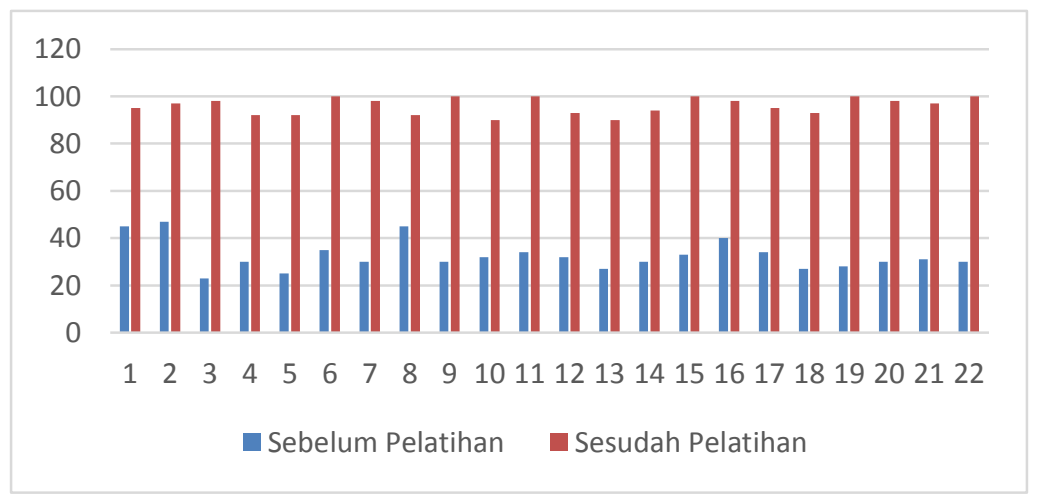

Gambar 10. Grafik Pemahaman Peserta Sebelum dan Sesudah Pelatihan 
Pada Gambar 10 dijelaskan bagaimana peningkatan pemahaman peserta sebelum dan sesudah penggunaan aplikasi. Metode ini dilakukan dengan cara memberikan kuisioner kepada mitra sebelum dan sesudah pelatihan. Hal ini ditujukan untuk melihat seberapa besar pemahaman peserta akan materi pelatihan. Adapun detail dari grafik di atas bisa dilihat pada tabel berikut.

Tabel 3. Keterangan dari Grafik 10

\begin{tabular}{|c|c|}
\hline NO & Point Penilaian \\
\hline 1 & Materi sesuai topik pelatihan \\
\hline 2 & Susunan materi yang sistematis \\
\hline 3 & Aplikasi Mudah Digunakan \\
\hline 4 & $\begin{array}{l}\text { Materi / modul pelatihan sangat mudah dipahami dan menarik bagi peserta } \\
\text { pelatihan }\end{array}$ \\
\hline 5 & Materi dapat diterapkan \\
\hline 6 & Materi meningkatkan pengetahuan dan kemampuan peserta pelatihan \\
\hline 7 & Persiapan instrukur dalam membawakan materi pelatihan \\
\hline 8 & Kompetensi instruktur \\
\hline 9 & Kemampuan didalam penyampaian materi sesuai dengan waktu yang tersedia \\
\hline 10 & Kemampuan instruktur dalam menjawab pertanyaan peserta pelatihan \\
\hline 11 & Kejelasan penyampaian materi oleh instruktur \\
\hline 12 & Kemampuan komunikasi secara lisan dengan peserta pelatihan \\
\hline 13 & Kemampuan penilaian secara obyektif kepada peserta pelatihan \\
\hline 14 & $\begin{array}{l}\text { Kemampuan instruktur didalam menciptakan suasana aktif dan komunikatif pada } \\
\text { waktu pelatihan }\end{array}$ \\
\hline 15 & Kejelasan suara dan intonasi instruktur didalam membawakan materi pelatihan \\
\hline 16 & Metode pelatihan sesuai dengan materi \\
\hline 17 & Metode membantu penyerapan materi oleh peserta pelatihan \\
\hline 18 & Metode pelatihan mendukung peserta lebih proaktif \\
\hline 19 & Terdapat simulasi pemecahan masalah \\
\hline 20 & $\begin{array}{l}\text { Evaluasi kemampuan dan pengetahuan peserta pelatihan sebelum dan sesudah } \\
\text { pelatihan }\end{array}$ \\
\hline 21 & Metode pelatihan sesuai dengan materi \\
\hline 22 & Kurikulum terarah \\
\hline
\end{tabular}

Pada tabel 6 ini akan menjelaskan indikator-indikator apa yang dinilai dalam pelatihan ini. Secara umum indikator penilaian meliputi tentang materi yang disampaikan, teknik penyampaian materi. Tingkat pemahaman materi peserta dan seberapa besar IBM ini memberikan manfaat terhadap mitra.

\section{KESIMPULAN}

Aplikasi Keuangan (Smart Excel) ini sangat efektif untuk melakukan rekap pembayaran keuangan terhadap siswa sekolah. Aplikasi ini mudah digunakan dan dapat dipahami lebih baik. Seiring dengan peningkatan fitur software di kemudian hari perlu dilakukan penambahan kegiatan untuk mengupgrade dari versi software yang digunakan. 


\section{UCAPAN TERIMA KASIH}

Penulis mengucapkan terima kasih kepada Fakultas Ilmu Komputer (FASILKOM) Universitas Lancang Kuning (UNILAK) yang telah sepenuhnya membiayai pengabdian ini melalui Skim pendanaan Pengabdian Anggaran Pendanaan Belanja Fakultas (APBF) FASILKOM-UNILAK tahun 2020.

\section{DAFTAR PUSTAKA}

Angelia, M., Setiono, K., Setevannus, Y., \& Andry, J. (2018). Audit Sistem Informasi Absensi Pada Pt Sinar Pratama Agung Menggunakan Kerangka Kerja Cobit 4.1. Vol. 4, No(2), 163-171. http://ejournal.uin-suska.ac.id/index.php/RMSI/article/view/5690

Hasan, M. A., \& Rianto, R. (2017). Analisa dan Perancangan Sistem Keuangan Tandan Buah Sawit (TBS) pada Koperasi Sumber Rezeki Kampung Rantau. Indonesian Journal of Computer Science, 6(2), 206-217. http://ijcs.stmikindonesia.ac.id/index.php/ijcs/article/view/39

Hasan, M. A., Supriadi, S., \& Zamzami, Z. (2017). Implementasi Algoritma Fisher-Yates Untuk Mengacak Soal Ujian Online Penerimaan Mahasiswa Baru (Studi Kasus : Universitas Lancang Kuning Riau). Jurnal Teknologi Dan Sistem Informasi, 3(2), 291. https://doi.org/10.25077/TEKNOSI.v3i2.2017.291-298

Hasan, M. A., \& Zamzami, Z. (2017). Rancang Bangun Sistem Informasi Pelayanan Angkutan Terminal Kota Pekanbaru Berbasis Online. Jurnal Ilmu Komputer, 6(1), 8-14. https://doi.org/10.33060/jik/2017/vol6.iss1.40

Kosasi, S., \& Eka Yuliani, I. D. A. (2015). Penerapan Rapid Application Development Pada Sistem Penjualan Sepeda Online. Simetris : Jurnal Teknik Mesin, Elektro Dan Ilmu Komputer, 6(1), 27. https://doi.org/10.24176/simet.v6i1.234

Kustiyahningsih, Y. (2013). Perencanaan Arsitektur Enterprise Menggunakan Metode Togaf ADM (Studi Kasus : Rsud Dr.Soegiri Lamongan). Prosiding Seminar Nasional Manajemen Teknologi XVIII, 1-8.

Nasution, N. (2018). Sosialisasi Aplikasi Manajemen Penelitian Dan Pengabdian Berbasis Online Di Lppm-Unilak. Dinamisia: Jurnal Pengabdian Kepada Masyarakat, 2(2), 107-112. https://doi.org/10.31849/dinamisia.v2i2.1256

Nasution, N., \& Hasan, M. A. (2019). Ibm Pelatihan Cms Content Dan Digital Jurnalistik. Dinamisia : $\begin{array}{llll}\text { Jurnal Pengabdian Kepada } & \text { Masyarakat, } & 3(1), & \end{array}$ https://doi.org/10.31849/dinamisia.v3i1.1482

Nasution, N., Hasan, M. A., \& Setiawan, D. (2018). Pelatihan Pembuatan Aplikasi Android Sebagai Bekal Technopreneurship Untuk Peningkatan Daya Ekonomi Mandiri Alumni Smk Di Pekanbaru. Jurnal Pengabdian Masyarakat Multidisiplin, 1(3), 219-234. https://doi.org/10.36341/jpm.v1i3.436

Nasution, N., Hasan, M. A., \& Setiawan, D. (2020). Sosialisasi Aplikasi Ujian Masuk bagi Calon Siswa Baru Universitas Lancang Kuning. Jurnal Laporan Abdimas Rumah Ilmiah, 1(1), 68-73. http://jlari.org/index.php/jlari/article/view/19 